toothless ichthyosaurs is the nature of their food, which was almost certainly different from that of their stronglv toothed Liassic precursors, which appear to have been less well adapted for a pelagic life. It is not that the heavily armoured ganoid fishes of earlier formations had died out, as witness the presence of Lepidotus in the Oxfordian; and it may be that the ichthyosaurs of that epoch fed on belemnites instead of fish. If this be so, the Cretaceous toothless pterodactyles may likewise have made an analogous change in their diet, as compared with that of their well- damage at particular seasons. The observations recorded in this paper are of general interest, as the plant chosen for investigation was wheat, and the following are the chief results obtained.

Grass culms show in general two periods of growth-a preparatory period characterised by short internodes carrying scales or under-sized leaves, and a subsequent period of vigorous growth characterised by long internodes carrying well-developed leaves. In the average primary culm ( $\mathrm{r}$ ) the same number of leaf-bearing internodes is produced in these two

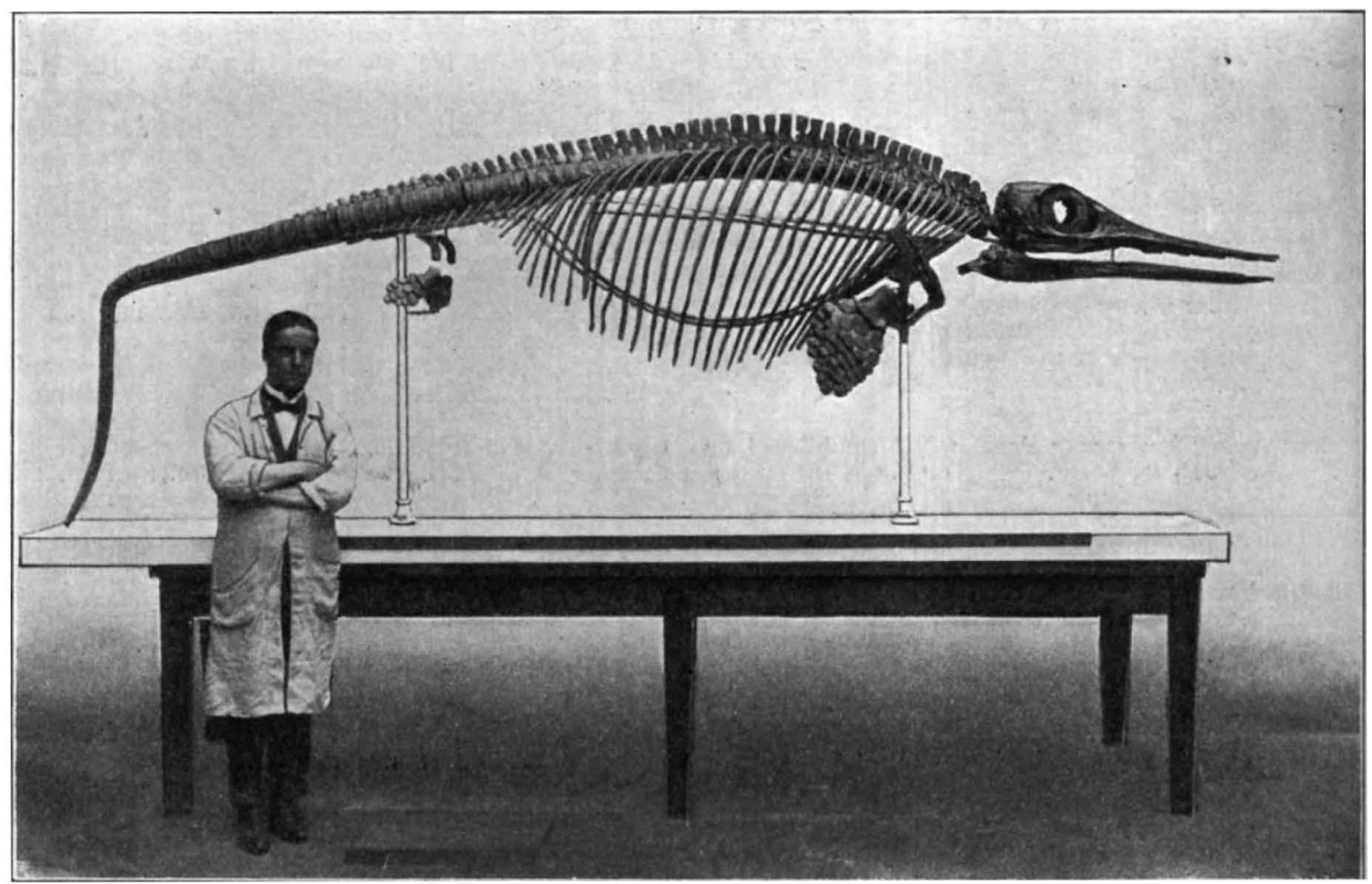

Skeleton of Ophthalmosaurus icenicus from the Oxford Clay exhibited in the Geological Department of the British Museum (Nat. Hist.). Reproduced from the Museums Journal.

toothed ancestors, only in their case it may have been merely from hard-scaled to soft-scaled fishes.

R. L.

\section{DEVELOPMENT OF THE CULMS OF} GRASSES.

A $\mathrm{N}$ important paper by $\mathrm{Mr}$. R. S. Hole, forming A Forest Bulletin No. 25 of the Indian Forest Research Institute, deals with the development of the culms of grasses. The author points out that the generalisation, based upon the study of grasses and cereals of temperate climates, that the culms are annual does not hold good in the case of various economically important species which are dominant in the savannah lands of Indian forests; hence the discovery of a method by means of which the age of the culms of any particular species can be readily determined is a matter of practical importance bearing directly on such questions as the selection of the best rotation to adopt in the case of grasses worked for paper pulp or the liability of certain species to fire NO. $236 \mathrm{I}$, VOL. 94] stages, but the period of preparatory growth is approximately three-fourths of that of vigorous growth; (2) the average number of long internodes produced is approximately equal to the number of months in the period of vigorous growth, and this number is practically the same whether calculated from the primary culms alone, from the axillary culms alone, or from a mixture of these as found in the final crop. In the older axillary culms (I) both growth periods, but more especially the preparatory period, are shorter than those of the primary culms, and there is little difference between the two classes of culms as regards the date of ripening grain; (2) the number of leaf-bearing short internodes is approximately half the number of the long internodes, and the preparatory period of growth is approximately half the vigorous growth period. The author thus obtains for both annuai and perennial grasses the generalisation that the average number of leaf-bearing long internodes produced in a culm-that is, excluding the apical segment terminating in the inflorescence-is approximately equal to the number of months comprising the period of vigorous growth. 